\title{
Identifying Contextual Socio-Cultural Attributes as Predictors of User Satisfaction: A Study in Transformed Public Housings in Nigeria
}

\author{
Abubakar Danladi Isah ${ }^{1}$, Tareef Hayat Khan ${ }^{2} \&$ Howard Davis $^{3}$ \\ ${ }^{1}$ Faculty of Built Environment, Department of Architecture, Universiti Teknologi Malaysia, Malaysia \\ ${ }^{2}$ Pusat Kajian Alam Bina Melayu (KALAM), Institute for Smart Infrastructure and Innovative Construction \\ (ISIIC), Faculty of Built Environment (FBE), Universiti Teknologi Malaysia (UTM), Malaysia \\ ${ }^{3}$ Department of Architecture, School of Architecture and Allied Arts, University of Oregon, USA \\ Correspondence: Abubakar Danladi Isah, Faculty of Built Environment, Department of Architecture, Universiti \\ Teknologi Malaysia, Malaysia. E-mail: arcmuzaifa@futminna.edu.ng
}

Received: July 9, 2015 Accepted: October 16, 2015 Online Published: October 28, 2015

doi:10.5539/ass.v11n25p165 URL: http://dx.doi.org/10.5539/ass.v11n25p165

\begin{abstract}
Transformation of houses is common, especially when households inhabit them for a considerable period of time. However, the scale of transformation might vary. Public housing in Nigeria has seen large scale transformations, and started to generate wide attention. The transformation phenomenon is often attributed to the exclusion of socio-cultural values in initial design that eventually results in unguided densification. But at the same time, house transformations arise from people's desires to satisfy their own ever changing housing needs. Using transformation as a sign of dissatisfaction, this study was an attempt to identify local socio-cultural attributes lack of which result in such transformations. Conditional sampling was adopted in order to find respondents across Nigeria. Socio-cultural attributes were identified from background study and were used in structuring a questionnaire-based survey. Findings from univariate and psychometric analysis based on the survey indicated that social activities and family structure were the two most significant socio-cultural attributes that guide residents' transformation decisions in public housing adjustments. This finding also appeared to be crucial as initial layouts proved not to lead to users' satisfaction. These results might be useful for prospective developers who are explicitly seeking a successful and sustainable delivery system.
\end{abstract}

Keywords: socio-cultural, user satisfaction, public housing, transformation

\section{Introduction}

Housing transformation is a natural consequence of inhabitation (Tipple, 1999). Transformation is operationally defined in this article as the process whereby the house dweller makes or institutes physical changes to the dwelling in order to meet needs that arise in the course of living in the dwelling. Transformation incidents can results from both internal and external reasons. The internal reasons can generate from demographic or economic changes, while the external reasons can generate from changes in the physical condition of the house. The nature and the degree of transformation vary from context to context. However, study showed that internal reasons are the major contributors towards transformation decisions (Khan, 2014a). Many researchers have tried to investigate the reasons, consequences and proposed guidelines for housing transformation. Studies on public housing transformation deserve considerable attention as it involves a significant amount of resources from the public sector. Especially in developing countries where resources are limited, it might create problems from the point of view of policy makers if it later results in any unwanted development.

Seek (1983) argued that housing stress is relieved after housing transformation, and that a transformed house is actually a reflection of a satisfied household. Khan (2014b) added that though housing stress can reach critical points many times during the life of a household large- scale transformation is likely to occur only a few times. Therefore, by studying a mature house that has gone through several transformations by a particular household, there is more possibility to uncover the attributes that contribute to housing transformation, hence user satisfaction. Moreover, occupants' needs become obvious through their domestic chores in the dwelling (Habraken, 1975). It is often claimed that socio-cultural attributes, especially context-specific ones, get less attention during such investigations in public housing design. Previous contributions in housing research in 
Nigeria focussing on housing satisfaction (Ukoha \& Beamish, 1997), housing policy (Ayoola \& Amole, 2014; Jiboye, 2011a, 2011b; Ogu \& Ogbuozobe, 2001), housing adjustment (Ibem et al., 2012), housing quality (Jiboye, 2004) and housing evaluation (Jiboye, 2010; Odediran et al., 2013) have identified the need for socio-cultural inclusion in public housing design. This study aims to fill that research gap by searching for socio-cultural attributes behind user satisfaction through studying transformed public housing units. It is an attempt to strategize guidelines for future designs of public housing.

\section{Background Study}

Previous Nigerian housing policies have been widely rejected by public housing residents resulting in execution of large scale housing transformations that sometimes undermined the quality of living within neighbourhoods. Scholars have attributed this to socio-cultural exclusion and inconsistency in Nigerian housing policy (Ibem et al., 2011; Olotuah \& Bobadoye, 2011; Olowoyo \& Khan, 2012). In spite of these challenges, public housing estates have been promoted and several state governments in Nigeria have participated in housing delivery via public housing, because it provided housing for disadvantaged people (Clapham et al., 2000). It is important to note that $40 \%$ of Nigerians who live in urban centres face serious complex housing problems due to overcrowding; with $75 \%$ of the urban residents living in slums. A full $60 \%$ of Nigerians lack decent homes (Olotuah \& Bobadoye, 2011).

This study first reviews previous studies on socio-cultural attributes behind housing transformation. The list of socio-cultural attributes from those studies was then modified in order to develop the research instrument in selected housing estates. Socio-cultural issues can be tangible and intangible as well as dynamic due to changing circumstances of inhabitants. Therefore identifying the core socio-cultural attributes of user satisfaction became crucial. There were three challenges. Firstly, there are three major regions in Nigeria, Northern, Southern, and Eastern, each having its distinct cultural identity. Only the Northern region was picked for the study, to remove more complicated issues created by bigger levels of cultural diversity. Still, there are six major ethnic groups in Northern Nigeria: Hausa, Fulani, Kanuri, Nupe, Tiv, and Gwari. However, they are assumed to have many common attributes, and they were represented proportionately in the sample, so that the outcomes reflect the region as a whole. Second, living in the city limits the actual level of cultural values that can be carried from the countryside. Therefore, there was a need to filter such issues of user satisfaction that were not relevant at the urban level. And third, there was a need to identify the tangible and intangible components of socio-cultural attributes. This study mainly focused on the tangible ones.

\subsection{Housing Satisfaction and Housing Transformation}

Housing satisfaction is one of the fundamental concepts behind housing transformation. Evaluating the impact of users' decisions on housing arrangement over time on housing satisfaction is a necessary constituent of Environmental Impact Assessment (EIA) and Post Occupancy Evaluation (POE) that guide subsequent designs and policies. Previous studies' evaluations have shown that homogeneity in public housing layout has excluded users' needs and requirements (Kaitilla, 1993) with dissatisfaction due to lack of sensitivity towards socio-economic attributes (Ibem \& Amole, 2013; Mohit et al., 2010). Interestingly, Salleh (2008) found Malaysian low-cost housing users to be generally satisfied with housing neighbourhood facilities but dissatisfied with the attributes of housing units, a trend not common in the study area under consideration. In addition, daily use of outdoor space was discovered to be fundamental in designing residential layouts in Jordan (Abu-Ghazzeh, 1999). In contrast to the homogenous housing units that are common with public housing (Tipple 1999); (Khan, 2014b) has discovered a consistent heterogeneity in the transformation of self-built neighbourhoods in Dhaka with variations of layout configurations existing on the same scale. These actions can be correlated with the level of users' involvement or consideration in the housing process consequently leading to housing satisfaction.

Furthermore, in the Netherlands and Denmark housing characteristics, quality and cost have influenced homeowners housing satisfaction (Elsinga \& Hoekstra, 2005). Rapoport (2000), described family relations, family structure and social networks as integral socio-cultural components of culture that determine users' housing satisfaction. In Nigeria, housing dissatisfaction has been credited to socio-cultural exclusion in housing design (Ibem \& Amole, 2013; Ukoha \& Beamish, 1997). Therefore, all these attributes are vital in identifying homeowners' satisfaction derived through public housing transformation. Moreover, Maina (2013), has established correlation between transformation and user's efficacy of space in a community in this study setting, the absence which would have made residents abandon their dwellings.

\subsection{Transformation in Public Housing}

Though public housing may not always allow much freedom for transformation, this phenomenon has progressively proven to be inevitable as the housing process itself has remained dynamic in Nigeria. Factually, 
the composition of houses and subsequent transformations are replications of socio-cultural relations in advancing housing civilization (Franklin, 2006). Consequently, reflecting family values illuminates preferences and choices in defining norms and standards (Rapoport, 2000). According to Seek (1983), socio-economic factors influence households' housing decisions with a shift from actual provision to a desired level of consumption. This could be referred to in a conventional definition as transforming a 'house' to a 'home'. In other words, transformation has the capacity "to turn a house into a home" by adding a sense of attachment to the physical attributes of the house.

Olotuah and Bobadoye (2011) revealed the failure of prototype housing in Nigeria, blaming the prominent noticeable uniformity of house form across regions, as houses quickly lose their planned concepts to unplanned layouts upon possession. Ikejiofor (1999) added that there is a general lack of awareness in both the supplier and the users, as the public sees a house as a product entirely completed before use. It seems that a conventional description of a housing package as a modern house provided by the government is just a minimum required physical plan layout and construction, negating the traditional concept of a house developing from a basic core and growing gradually along with users' needs and means.

\subsection{Socio-cultural Determinants in Housing Transformation}

From (Jiboye, 2004; Rapoport, 1969, 2000), the relationship between family structure, lifestyle, values, activities and identity and the house ultimately influence user satisfaction. this comes about because these parameters incorporate the smaller socio-cultural attributes of housing transformation such as gender, income, tenure status, level of education, age (Ayoola \& Amole, 2014). Family activities vary over time, between groups, and express culture distribution in a system. In effect, inhabitants' activities greatly define a dwelling as a home (Rikko \& Gwatau, 2011). Family structure influences spatial arrangement, matching housing and household; and leads to change of space use with the changing family unit (Rapoport, 2000). For instance, attaining adulthood and getting married impose changes to the family structure which are ultimately replicated in housing transformation (Khan, 2014a). Family values and social identities also contribute to the housing transformation as changes in values and identities lead to expansion or reduction of space requirements (Khan, 2014b). Social activities were also found to be determinants of socially-supportive building design; for example, allotted spaces had the potential to be used for communal social setting as showed in clustered dwelling units by Regnier (2003). Similarly, family lifestyle and identity, reflected in status, employment and level of education has inter-generational transmission in home ownership achievement (Mulder \& Lauster, 2010).

Accordingly, Jiboye (2004), argued against the lack of consideration of users' socio-cultural attributes in housing policy, and suggested the importance of inclusion of cultural preferences and peculiarities in physical dwellings' layouts. Also, according to Gotham (2003), social change is viewed from the point of view of 'relation' and 'conflict' in socio-spatial concepts. Thus, the nature of public housing transformation has been argued to be a consequence of socio-cultural exclusion in initial designs. In the same way, Dincyurek and Turker (2007) consider the design of buildings with socio-cultural attributes in mind as efforts to preserve traditional environments. Self-expression and emotional attachments to spaces are life-long characteristics that keep manifesting spatially in the lifespan of households until they fulfil the task of expressing values in their dwelling layout (Khan, 2014b).

Some studies related to strategy-making equally relate to transformation. Ikejiofor (1999) pointed out the need for a dynamic delivery system especially for low-income groups, allowing them to build their house incrementally after delivery of the basic shelter package comprising the essentials of a plot, infrastructure, and a basic unit. He implied that the procedure should involve gradual space (plot) utilization, with the physical growth of the basic unit not restricted to a conceived plan, and in addition, allowing people to manage their own funding. At a smaller scale the growth options may remain limited and it therefore could be easier to identify the development potentials and limitations.

In light of the above, the selected socio-cultural attributes were tested in this study to determine their contributions to housing transformation and subsequent housing satisfaction.

\section{Methodology}

In examining the socio-cultural attributes of public housing transformation, psychometric analyses were conducted in line with (Anderson \& Gerbing, 1992). Exploratory analysis, with reliability testing via Cronbach's alpha, was adopted in establishing the internal consistency of the tool. Factor analysis using principal component extraction was applied in establishing the factor coefficient of the item variables in order to extract the weak items. Confirmatory factor analysis (CFA) was conducted to ascertain the loading coefficients of variable items in determining their strength in the phenomenal construct. The strength manifested in the factor loadings of the 
various factors were individually considered in the factor analysis. Subsequently, the output of the confirmatory factor analysis led to the construction of the socio-cultural composite model of user satisfaction in public housing transformation using the structural equation model (SEM). Furthermore, regression analysis was then performed to estimate the coefficient of each of the socio-cultural attributes in predicting users' satisfaction in public housing transformation.

\subsection{Respondents}

Information for this research was collected through a regional housing survey limited to the Northern states of Nigeria as part of a regional study on housing transformation process. The survey adopted stratified sampling with the inclusion of five states covering six major ethnic groups proportionately selected so that the desired population is socio-culturally and geographically represented. The six dominant ethnic groups have historically occupied particular states in the region. Hausa ethnic groups are found in Sokoto and Katsina states; Fulani is predominant in Adamawa state; Kanuri is concentrated in Borno state; Tiv in Benue state; while Nupe and Gwari can be found in Niger state (Mustapha, 2006).

Next, within these states, the capitals were chosen as public housing in Nigeria is concentrated in state capitals. Finally, two housing estates in each state capital considered were selected based on conditional random sampling. The conditions included: the estate is sited in the state capital, the age of the estate would not be less than five years or more than fifty years, and the occupier is the owner of the house. For each of the housing estates, a simple random sampling technique was used in selecting transformed houses. In the final sampling stage, 30 households in each estate, totalling 300 , were selected by a random sampling of transformed houses adequate to represent the population. This is supported by the adoption of roasoft statistical software in sample size calculation and the minimum returned sample size table for statistical analysis (Bartlett et al., 2001) in order to justify the selected sample size.

The house types within the study areas were either semi-detached blocks of flats or bungalows with initial design layout ranging from one to three bedrooms. The survey questionnaire was delivered house-to-house. A total of 297 respondents are in the final sample received the questionnaire forms. However, the sample used included only 276 respondents as 9 forms were discarded due to missing information while 12 were not returned by the respondents.

\subsection{Survey Instrument}

Ukoha and Beamish (1997) assessed occupants' satisfaction with public housing in Abuja, Nigeria measuring length of stay, household size, tenure and number of habitable spaces as part of the observed variables . Similarly, Jaiyeoba and Aklanoglu (2012), while discussing socio-economic issues in socially produced low income housing in Nigeria, examined the level of education, family size, number of habitable rooms and marital status as social attributes of the low income group in housing satisfaction. The study focused on the concept of ideological and social elements of culture related to components of the built environment in housing research suggested by Rapoport (2000). Thereafter, factors were generated from these previous housing studies and modified in developing the questionnaire for this study. Consequently, a five point-Likert scale instrument measuring household activities, family structure, lifestyle, identity and values as culture components was used in examining space organisation of housing units having been tested in previous studies and in tune with environment-behaviour studies.

The five point-Likert scale instrument shown in the appendix was used as it gives the respondents the opportunity to express their feelings freely (Barnett, 1991). The instrument includes a household research questionnaire developed in English by the researcher based on available questionnaires, inventories tested and documented in previous studies and found useful for this study. The questionnaire was divided into two major sections of demographic information and the Likert-scale section with culture attributes as sub-sections. Items in each sub-section are questions related to the cultural attribute of the group developed from previous tested research. Table 6 shows observed variable items that are significant after subjecting the data to psychometric analysis.

\subsection{Limitations}

Due to the breadth of cultural determinants of housing and the time limit for this research, the research is limited to socio-cultural elements observed, excluding economic and physical features. Although these factors are related to decisions in housing transformation, the study concentrated on activities and activity spaces in the relationship of culture to space configuration. It therefore reports the association between socio-cultural elements and the spatial arrangement of transformed houses. It equally focused observation on variables of spatial 
importance to the cultural backgrounds being studied. Daramola (2006) acknowledges that dutiful designers make function a starting point. In spite of the limitations, this research has drawn data from across states and different cultural groups in assessing user satisfaction through transformation across the region. The research identifies the dynamic socio-cultural elements that account for the transformation of planned public housing to unplanned layout in public housing design, thus facilitating an examination of the benefits of housing transformation in ensuring user satisfaction.

\subsection{Measures}

\subsubsection{Dependent Variable}

The outcome of this research is the establishment of socio-cultural characteristics of user satisfaction in the transformation of planned concepts of public housing to unplanned layouts upon user ownership / control.

\subsubsection{Independent Variables}

The independent variables used in examining user satisfaction in housing spatial transformation include family structure, social activities, family lifestyle, family values and social identity. However their periodic changes over time were not accessed, but only their state at the time of survey. The time dimension of the existence of the estates was determined from the year of establishment.

\subsubsection{Method of Analysis}

Housing is considered as part of built environment, whereas the culture of its inhabitants as behaviour in tune with Rapoport's theory of environmental behaviour relations (EBR) (Rapoport, 2000). The bedrock of the theory seeks relating components of the built environment with attributes of culture in housing research. This study adopted cultural expressions that included values, lifestyle, family structure, identity and domestic chores (activities).

Consequently, for precision and feasibility the outlined components of culture were adopted and related with space organisation as an attribute of housing in examining socio- cultural effect in transforming public housing from planned to unplanned layouts towards achieving housing satisfaction.

Table 1. Variables definition in the analysis of socio-cultural characteristics

Variable Operational definition

\section{Outcome variable Dependent attribute}

User satisfaction in transformed housing units

Antecedents independent predictors

Socio-cultural attributes

1. Social activities

2. Family structure

3. Family values

4. Family life style

5. Social identity

Time variant covariates

Age of building

Duration of residency

Family size
Socio-cultural characteristics that account for transformation towards user satisfaction.

Common family activities that require functional space; Children's play, visitors' accommodation, gatherings \& relaxation areas.

Family organisation; Resident relation, marriages, child adoption, gender privacy, adolescent children segregation \& period of residency.

Basic norms with respect to; Neighbourhood interaction, domestic activity distribution \& domestic servants' accommodation.

Communal relationships with neighbours, outdoor relaxation, change in economic status \& keeping pets or domestic animals.

Identifying with ethnic background; reflecting ethnic space use, familial meetings, family status reflections, ethnic identity \& previous public housing experience.

Estates occupied 5-50years.

Period that household have lived in the housing unit.

Number of family members at the time of survey. 


\section{Results and Findings}

\subsection{Univariate Analysis}

Demographic analyses of family size and residency duration presented in Figures 2 and 3 respectively show that family size and the period of stay are strongly significant in justifying spatial transformation in achieving user satisfaction. It is observed that about $51 \%$ of the respondents surveyed have a family size greater than ten (10) members. Although the family size at the point of occupation was not examined there is the tendency that household sizes upon occupation are small. However, the current size is not consistent with expected occupancy rate of the initial public housing design that comprised of 1,2, and 3 bedrooms. This change in family size is accounted for by marriages, childbirth, resident relations, children's growth into adolescence and domestic servants living within the residential unit. This outcome defines the family distribution which may have accounted for the need for spatial transformation of initial design layout. Moreover, the target group who are low income earners are characterised with large nuclear and sometimes extended families (Maina, 2013).

Likewise, $66 \%$ of the studied population has lived beyond five (5) years in their houses at the time of survey. Most likely, this outcome is an indication that tenure ownership may have encouraged the gradual spatial transformation of housing units to its present state. The outcome of both factors is not inconsistent with findings of previous related studies (Seek, 1983; Tipple, 2000). Seek (1983) observed family life cycle to have combined significantly socio-cultural characteristics of household with progressive changes at different life cycle stages and consequent space demand corresponding with number of years of occupancy. Tipple (2000) found association between household size and structure which entailed the demand for increase in housing space through transformation process in developing countries.

\subsection{SEM Multivariate Analysis}

\subsubsection{Exploratory Factor Analysis (EFA)}

In the first instance, item scaling was conducted via reliability analysis and Cronbach's Alpha of .873 was achieved and presented in table 2. The figure is above the threshold of 0.70 recommended by Nunnally (Nunnally, 1994) an indication of sufficient reliability of the instrument used. This was followed by descriptive factor analysis with Kaiser-Meyer-Olkin (KMO) and Bartlett's test of sphericity to examine the strength of the variable items in the instrument having grouped them into factors guided by previous studies. A total of 32 questionnaire items with demographic items were used for the study. The Likert scale items were grouped into five (5) factors of social activities with 8 items, family structure with 6 items, family values with 7 items, family lifestyle with 5 items and social identity with 6 items. Items that exhibited factor loadings less than 0.40 (Table 4 ) were considered weak for the construct and thereby excluded from further analysis. The final composite model exhibited good model fit, with the normed chi square of $x 2=2.266$ (Bagozzi \& Yi, 1988; Klem, 2000). The goodness of fit index GFI recorded is 0.850 within the recommended value of $\geq 0.8$ (Chau \& $\mathrm{Hu}, 2001$ ), comparative fit index CFI is 0.782 , and Root mean square error equals 0.068 (Steiger \& Lind, 1980), also within acceptable limit (ibid).

\subsubsection{Confirmatory Factor Analysis (CFA)}

Secondly, 29 items with loading $\geq 0.40$ were considered for confirmatory factor analysis in order to develop the socio-cultural construct of user satisfaction in housing transformation. All the socio-cultural factors were further subjected to confirmatory factor analysis. However, factors that do not show unique manifestation of single factor were considered weak and analysed at a composite scale. Thus, the CFA model first considered the factors of social activities and family structure which exhibited single factor manifestation with high factor loadings; then the factors of family value, family lifestyle and social identity which did not exhibit single factor manifestation; but rather indicated a composite factors manifestation. Therefore, the assumption that family values, family lifestyle and social identity can distinctively influence users' preference in predicting socio-cultural attribute was considered weak. Consequently, the final model that evolved from the confirmatory factor analysis is a composite of five factors of social activity with 8 items, family structure with 5 items, family values with 3 items, family lifestyle with 5 items and Social identity with 5 items. Furthermore, two composite were developed from the confirmatory factor analysis. They include the tangible composite with social activities and family structure as component factors; and the intangible composite which has family values, family lifestyle and social identity as component factors. Fig 3 shows proposed socio-cultural structural model of user satisfaction in housing transformation. 


\subsection{Correlation Analysis of Factors}

The strength of association among the five factors was examined using correlation analysis and presented in table 5. The result shows a notably high relationship between the tangible factors of social activities and family structure. Similarly, each of these tangible factors exhibited exceptionally strong association with family lifestyle-an intangible factor. The least association is observed between family structure and social identity. However, with the path coefficients $\geq 0.2$ all factors exhibit strong significance (Cohen, 1992a, 1992b) and are positively correlated. In effect, the significant association between social activities and family structure implies that household composition with the nature and types of household activities are strongly related. The implication is that spatial provisions should accommodate these social activities in order to achieve user satisfaction. Equally, family lifestyle is significantly related to both social activities and family structure which means family distribution and activities are dependent on the lifestyle adopted by the household. Hence family lifestyle is seen in household activities and structure. In contrast however, social identity and family values have less impact on family structure, thus requiring less priority in spatial consideration. The statistical analysis also shows significant association of social activities to social identity and family values indicating that household activities reflect values and identity. Therefore activity spaces echo household values and cultural identity.

In view of the foregoing analysis, household structure and activities represents a strong predictor of user satisfaction of transformed public housing. Their tangible attribute qualifies their reflection in spatial configurations. However, the time variant in the changes, which requires a two stage analysis, was not within the focus of this study. But it suffices to acknowledge that the transformed layout which was informed by the household structure and activities at the time of survey is inconsistent with the initial design layout.

Therefore developers and designers ought to consider indigenous and changing patterns of household structure and activities in the housing layout and housing consumption of public housing residents. Equally, policies on land allocation and design of public housing units should include provision for future spatial changes, so that in the event of transformation, there would not be restrictions to spatial extensions which usually lead to densification as observed in the study areas.

\subsection{Regression Analysis}

Remarkably, regression weights are within the range of model fit while the regression analysis shows high significance at $<.01$ levels for both observed item variables and factors. Also, the critical ratio value greater than 1.96 which was achieved for variables suggests a significant relationship for further examination. This indicates an acceptable equation appropriate for user satisfaction via the transformation phenomenon. However, this was achieved after Ramsea reset test was performed and 3 item variables whose measurement error had multiple modification recommendation were eliminated. This is because there is no strong theoretical back up for the suggested modifications. In effect, all hypothesized paths were accepted fit and presented in Table 6.

\section{Discussion}

Findings indicate that social activities matter in housing satisfaction. As expected, accommodating overnight guests and social gatherings are significant variables. This is in line with the custom of honouring guests that is common among the northerners, where close family guests and social events are preferred to be hosted within dwelling units and considered as household activities. Therefore designing for this category would require provision of space for these activities.

On the effects of family structure in determining user transformation towards user satisfaction, children's growth into adolescent, welcoming new members through marriages and adoption, residing family relations may have accounted for visual and physical privacy needs which resulted into housing transformation in acquiring additional space towards achieving satisfaction. This confirms the findings by both Seek (1983) and Tipple (2000) who found change in household demography with rise in the number of adults to be the reason for more space and privacy requirements in public housing transformation.

Family norms of living with domestic servants and interacting with neighbours particularly among the female folks may have informal spatial transformation. Household problems and experiences are commonly shared among neighbours from were beneficial outcomes are imitated. In the same vain, family lifestyle is sometimes influenced by the neighbourhood characteristics; for instance outdoor relaxation and living with domestic animals are common lifestyle practices across the region.

Changes in economic status of the family, particularly that of the house head, often manifest in additional responsibility such as additional marriages, employing domestic servants and adopting children which in turn lead to additional functional space requirements such as additional living spaces, which were not of priority 
earlier, suddenly become necessary for spatial transformation.

Although guest reception reflects cultural identity in African tradition, hosting of kinsmen and spatial arrangement in tune with cultural background is found to be important with transformers. In contrast however, reflecting cultural status of family, such as royalty and chieftaincy may not have influenced transformation as it is less significant. Similarly, most respondents were not influenced by previous knowledge of public housing as a good number of them were having their first experiences living in public housing.

The result from demographic analysis also revealed that public housing units with initial design of 1,2 and 3 bedrooms would certainly require spatial modification in meeting with the changing occupancy rate. Moreover, a greater percentage of respondents were occupying their houses on tenure ownership with residency beyond 6 years, which meant that over time, changing needs were translated into spatial changes in achieving satisfaction. Similarly, comparing the family size with the significant values recorded with the family structure supported the argument that family structure is influenced by family size. Even though the majority of the households were nuclear families, residents' relations and additional marriages caused an increase in the number of children, calling for additional spaces.

\section{Conclusion}

Overall, various socio-cultural determinants indicate that tangible socio-cultural factors of social activities and family structure are significant factors of user satisfaction in public housing transformation. This outcome might have resulted due to a direct link between spaces and activities with the tangible factors. Both family structures and social activities are significantly influenced by the lifestyle of the household in guiding the pattern of housing adjustment

In view of the findings, the provision of public housing and its gradual transformation should be accounted for by developers at the design stage. Then ranking factors with consideration of the characteristics and peculiarity of socio-cultural elements of the households require objective consideration of user's experiences in choice and households preferences in realizing spatial changes to their homes. Consequently, their curiosity and impetus in relating house design with family's socio-cultural needs; as well as meeting lifetime goals are critical to their housing satisfaction, and should be considered by prospective public housing designers. In doing this, a review of socio-cultural needs of prospective users' is important. This will guide developers both in form and arrangement of activity spaces. In addition, cultural indices are progressive just as houses are dynamic, therefore, there is necessity to determine short term and long term influences on socio-cultural components.

\section{Acknowledgments}

The authors sincerely acknowledge Research Management Centre (RMC) of the Universiti Teknologi Malaysia (UTM), and the Ministry of Education (MOE) of the Government of Malaysia for the funding of the research through Research grant no. Q.J130000.2421.03G20, Q.J130000.2509.07H37 and R.J130000.7909.4S104.

\section{References}

Abu-Ghazzeh, T. M. (1999). Housi ng layout, social interaction, and the place of contact in Abu-Nuseir, Jordan. Journal of Environmental Psychology, 19(1), 41-73. http://dx.doi.org/10.1006/jevp.1998.0106

Anderson, J. C., \& Gerbing, D. W. (1992). Assumptions and comparative strengths of the two-step approach comment on Fornell and Yi. Sociological Methods \& Research, 20(3), 321-333. http://dx.doi.org/10.1177/ 0049124192020003002

Ayoola, A., \& Amole, D. (2014). The value of housing among the Poor in Ilesa, Osun State Nigeria. Architecture Research 2014, 4(1A), 45-54.

Bagozzi, R. P., \& Yi, Y. (1988). On the evaluation of structural equation models. Journal of the Academy of marketing science, 16(1), 74-94. http://dx.doi.org/10.1007/BF02723327

Barnett, L. A. (1991). The playful child: Measurement of a disposition to play. Play \& Culture, 4(1), 51-74.

Bartlett, J. E., Kotrlik, J. W., \& Higgins, C. C. (2001). Organizational research: Determining appropriate sample size in survey research appropriate sample size in survey research. Information Technology, Learning, And Performance Journal, 19(1), 43.

Chau, P. Y., \& Hu, P. J. H. (2001). Information technology acceptance by individual professionals: A model comparison approach. Decision Sciences, 32(4), 699-719. http://dx.doi.org/10.1111/j.1540-5915.2001. tb00978.x

Clapham, D., Franklin, B., \& Saugères, L. (2000). Housing management: The social construction of an 
occupational role. Housing, theory and society, 17(2), 68-82. http://dx.doi.org/10.1080/140360900457740

Cohen, J. (1992a). A power primer. Psychological bulletin, 112(1), 155. http://dx.doi.org/10.1037/0033-2909.112. 1.155

Cohen, J. (1992b). Statistical power analysis. Current directions in psychological science, 1(3), 98-101. http://dx.doi.org/10.1111/1467-8721.ep10768783

Daramola, S. (2006). Affordable and functional housing in a developing economy: A case study of Nigeria. Journal of Land Use and Development Studies, 15(2), 23-28.

Dincyurek, O., \& Turker, O. O. (2007). Learning from traditional built environment of Cyprus: Re-interpretation of the contextual values. Building and Environment, 42(9), 3384-3392. http://dx.doi.org/10.1016/j.buildenv. 2006.08.007

Elsinga, M., \& Hoekstra, J. (2005). Homeownership and housing satisfaction. Journal of Housing and the Built Environment, 20(4), 401-424. http://dx.doi.org/10.1007/s10901-005-9023-4

Franklin, B. (2006). Housing Transformation: Shaping the Space of Twenty First century living. London; NewYork: Routledge.

Gotham, K. F. (2003). Toward an understanding of the spatiality of urban poverty: The urban poor as spatial actors. International Journal of Urban and Regional Research, 27(3), 723-737. http://dx.doi.org/10.1111/1 468-2427.00478

Habraken, N. J. (1975). Supports: An Alternative to Mass Housing. London: Architectural Press.

Ibem, E. O., \& Amole, D. (2013). Residential satisfaction in public core housing in Abeokuta, Ogun State, Nigeria. Social Indicators Research, 113(1), 563-581. http://dx.doi.org/10.1007/s11205-012-0111-z

Ibem, E. O., Aduwo, E. B., \& Uwakonye, O. (2012). Adequacy of incremental construction strategy for housing low-income urban residents in Ogun State, Nigeria. Built Environment Project and Asset Management, 2(2), 182-194. http://dx.doi.org/10.1108/20441241211280918

Ibem, E. O., Anosike, M. N., \& Azuh, D. E. (2011). Challenges in public housing provision in the post-independence era in Nigeria. International Journal of Human Sciences, 8(2), 421-443.

Ikejiofor, U. (1999). The God that Failed: A Critique of Public Housingin Nigeria, 1975-1995. Habitat International, 23(2), 177-188. http://dx.doi.org/10.1016/S0197-3975(98)00042-3

Jaiyeoba, B., \& Aklanoglu, F. (2012). Socio-economic Issues in 'Socially Produced' Low Income Housing: Theory and Case study in Nigeria. Procedia-Social and Behavioral Sciences, 50, 855-864. http://dx.doi.org/ 10.1016/j.sbspro.2012.08.087

Jiboye, A. (2004). The socio-cultural responsiveness of household size on housing quality in Osogbo, Nigeria. Anthropologist, 6(3), 169-174.

Jiboye, A. D. (2011a). Achieving sustainable housing development in Nigeria: A Critical challenge to governance. International Journal of Humanities and social science, 1(9), 121-127.

Jiboye, A. D. (2011b). Urbanization challenges and housing delivery in Nigeria: The need for an effective Policy framework for Sustainable Development. International Review of Social Sciences and Humanities, 2(1), 176-185.

Jiboye, D. (2010). Evaluating Users' Household-Size and Housing Quality in Osogbo, Nigeria. Ethiopian Journal of Environmental Studies and Management, 3(2), 77-85. http://dx.doi.org/10.4314/ejesm.v3i2. 59825

Kaitilla, S. (1993). Satisfaction with Public Housing in Papua New Guinea The Case of West Taraka Housing Scheme. Environment and Behavior, 25(3), 514-545. http://dx.doi.org/10.1177/0013916593253005

Khan, T. H. (2014a). Houses in Transformation Search for the Implicit Reasons. Cham Heidelberg New York Dordrecht London: Springer. http://dx.doi.org/10.1007/978-3-319-02672-5

Khan, T. H. (2014b). Living with transformation: Self-built housing in the city of Dhaka. Cham Heidelberg New York Dordrecht London: Springer. http://dx.doi.org/10.1007/978-3-319-00720-5

Klem, L. (2000). Structural equation modeling. In L. G. Grimm (Ed.), Reading and understanding MORE multivariate statistics (pp. 227-260). Jonh Willey \& Sons, New York: Wiley-Interscience, Publication.

Maina, J. J. (2013). Uncomfortable prototypes: Rethinking socio-cultural factors for the design of public housing 
in Billiri, north east Nigeria. Frontiers of Architectural Research, 2(3), 310-321. http://dx.doi.org/10.1016/j. foar.2013.04.004

Mohit, M. A., Ibrahim, M., \& Rashid, Y. R. (2010). Assessment of residential satisfaction in newly designed public low-cost housing in Kuala Lumpur, Malaysia. Habitat International, 34(1), 18-27. http://dx.doi.org /10.1016/j.habitatint.2009.04.002

Mulder, C. H., \& Lauster, N. T. (2010). Housing and family: An introduction. Housing Studies, 25(4), 433-440. http://dx.doi.org/10.1080/02673031003771109

Mustapha, A. R. (2006). Ethnic structure, inequality and governance of the public sector in Nigeria. United Nations Research Institute for Social Development.

Nunnally, J. C. (1994). Bernstein: Psychometric theory. McGraw-Hill, New York.

Odediran, S., Morakinyo, K., \& Adeyinka, B. (2013). An Assessment of Facilities and Materials Specification and Residential buildings in Nigeria. Journal of Building Performance, 4(1), 52-58.

Ogu, V. I., \& Ogbuozobe, J. E. (2001). Housing policy in Nigeria: Towards enablement of private housing development. Habitat International, 25(4), 473-492. http://dx.doi.org/10.1016/S0197-3975(01)00018-2

Olotuah, A. O., \& Bobadoye, S. A. (2011). Sustainable housing provision for the urban poor: A review of public sector intervention in Nigeria. The Built \& Human Environment Review, 2, 51-63.

Olowoyo, S. A., \& Khan, T. H. (2012). Effect of culture on Urban Housing Non-Occupancy: A case Study in Ondo, Nigeria. British Journal of Humanities and Social Sciences, 7(2), 50-63.

Rapoport, A. (1969). House form and culture. Englewood cliffs: Prentice-hall.

Rapoport, A. (2000). Theory, culture and housing. Housing, theory and society, 17(4), 145-165. http://dx.doi.org/ $10.1080 / 140360900300108573$

Regnier, V. (2003). Design for assisted living: Guidelines for housing the physically and mentally frail. John Wiley \& Sons.

Rikko, L., \& Gwatau, D. (2011). The Nigerian architecture: The trend in housing development. Journal of Geography and Regional Planning, 4(5), 273-278.

Salleh, A. G. (2008). Neighborhood factors in private low-cost housing in Malaysia. Habitat International, 32(4), 485-493. http://dx.doi.org/10.1016/j.habitatint.2008.01.002

Seek, N. (1983). Adjusting housing consumption: improve or move. Urban Studies, 20(4), 455-469. http://dx.doi. org/10.1080/00420988320080811

Steiger, J. H., \& Lind, J. C. (1980). Statistically based tests for the number of common factors. Proceedings of the 1980 annual meeting of the Psychometric Society, Iowa City, IA.

Tipple, G. (2000). Extending Themselves: User Initiated Transformations of Government-built Housing in Developing Countries. Liverpool University Press. http://dx.doi.org/10.5949/upo9781846313097

Ukoha, O. M., \& Beamish, J. O. (1997). Assessment of residents' satisfaction with public housing in Abuja, Nigeria. Habitat International, 21(4), 445-460. http://dx.doi.org/10.1016/S0197-3975(97)00017-9 


\section{Appendix A}

\section{Statistical results}

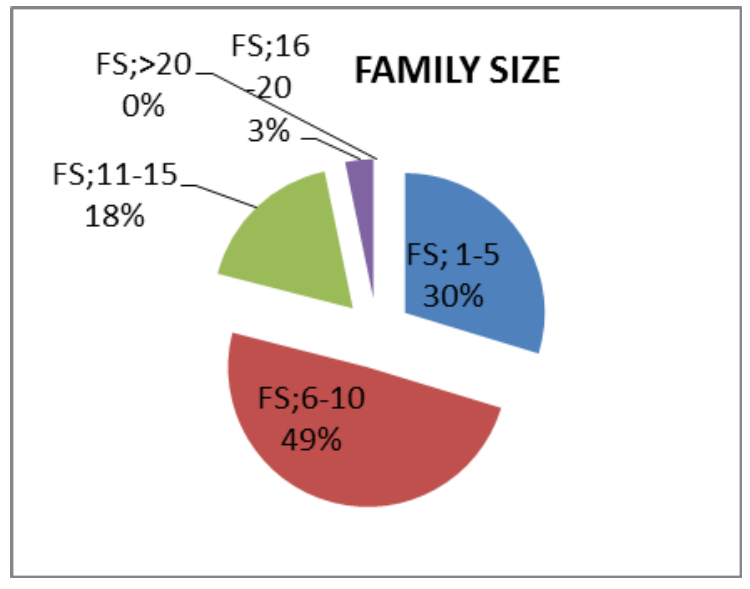

Figure 1. Family size of respondents

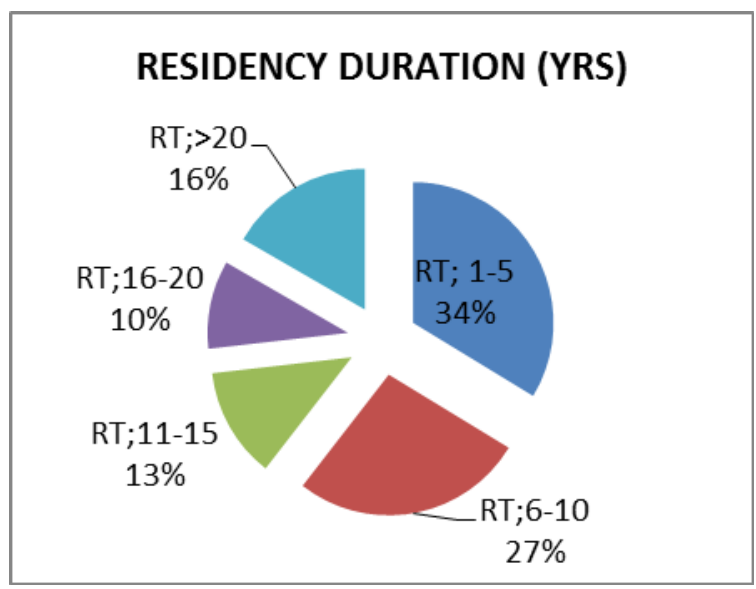

Figure 2. Residency duration of respondents

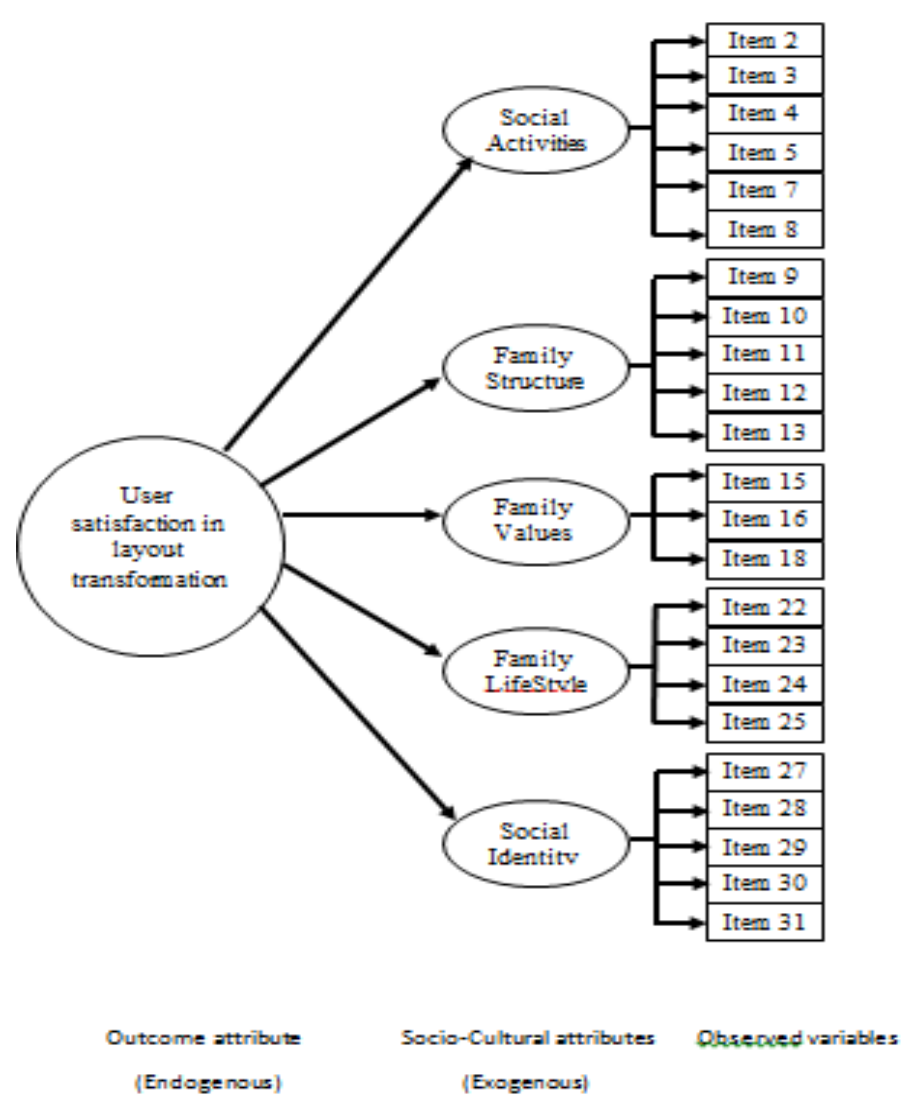

Figure 3. Proposed Socio-Culture composite model of user satisfaction in public housing transformation

Table 2. Reliability statistics

\begin{tabular}{lll}
\hline Cronbach's Alpha & Cronbach's Alpha Based on Standardized Items & N of Items \\
\hline .873 & .873 & 32 \\
\hline
\end{tabular}


Table 3. Scale statistics

\begin{tabular}{llll}
\hline Mean & Variance & Std. Deviation & N of Items \\
\hline 84.21 & 318.732 & 17.853 & 32 \\
\hline
\end{tabular}

Table 4. Factor analysis

\begin{tabular}{|c|c|c|c|c|c|c|c|c|c|}
\hline \multirow{2}{*}{\multicolumn{2}{|c|}{$\begin{array}{l}\text { Tangibles } \\
\text { Social activities }\end{array}$}} & \multicolumn{6}{|c|}{ Intangibles } & \multirow{2}{*}{\multicolumn{2}{|c|}{ Family Identity }} \\
\hline & & Family structure & & Family & des & Family & tyle & & \\
\hline Item 1 & .635 & Item9 & .616 & Item15 & .524 & Item 22 & .627 & Item 27 & .750 \\
\hline Item2 & .557 & Item 10 & .583 & Item 16 & .507 & Item 23 & .532 & Item 28 & .692 \\
\hline Item3 & .541 & Item11 & .549 & Item 17 & .458 & Item 24 & .510 & Item 29 & .626 \\
\hline Item4 & .529 & Item 12 & .537 & Item18 & .450 & Item 25 & .509 & Item 30 & .498 \\
\hline Item5 & .504 & Item13 & .481 & Item19 & .361 & Item 26 & .460 & Item 31 & .481 \\
\hline Item6 & .464 & Item 14 & .424 & Item 20 & .260 & & & Item 32 & .418 \\
\hline Item7 & .440 & & & Item 21 & .193 & & & & \\
\hline Item8 & .429 & & & & & & & & \\
\hline
\end{tabular}

Table 5. Correlation analysis

\begin{tabular}{llll}
\hline Correlation between factors & & & Estimate \\
\hline Social Activities & $<-->$ & Family Structure & .820 \\
Social Activities & $<-->$ & Family Values & .798 \\
Social Activities & $<-->$ & Family Lifestyle & .855 \\
Social Activities & $<-->$ & Social Identity & .645 \\
Family Structure & $<-->$ & Family Values & .508 \\
Family Structure & $<-->$ & Family Lifestyle & .863 \\
Family Structure & $<-->$ & Social Identity & .420 \\
Family Values & $<-->$ & Family Lifestyle & .774 \\
Family Values & $<-->$ & Social Identity & .607 \\
Family Lifestyle & $<-->$ & Social Identity & .684 \\
\hline
\end{tabular}

Table 6. Regression analysis of hypothesised paths

\begin{tabular}{|c|c|c|c|c|c|}
\hline Hypothesized paths & & Estimate & & S.E. & Z-Value. \\
\hline Family Structure & $<---$ & User satisfaction in layout transformation & .772 & .132 & 5.864 \\
\hline Social Activities & $<---$ & User satisfaction in layout transformation & 1.000 & & \\
\hline Family Values & $<---$ & User satisfaction in layout transformation & .750 & .146 & 5.151 \\
\hline Family Lifestyle & $<---$ & User satisfaction in layout transformation & .895 & .145 & 6.183 \\
\hline Social Identity & $<---$ & User satisfaction in layout transformation & .925 & .146 & 6.342 \\
\hline
\end{tabular}

Notes. $\mathrm{p}<0.01$, significant

Table 7. Regression analysis

\begin{tabular}{llllll}
\hline Variable Items & Factors & Estimate & S.E. & Z-Value. \\
\hline Children Play Area & $<---$ & Social Activities & 1.000 & & \\
Overnight Visitors & $<---$ & Social Activities & .979 & .142 & 6.880 \\
Social gathering & $<---$ & Social Activities & .844 & .131 & 6.434 \\
Overstretched Facility & $<---$ & Social Activities & .679 & .133 & 5.108 \\
Female indoor relaxation & $<---$ & Social Activities & .846 & .134 & 6.299 \\
\hline
\end{tabular}




\begin{tabular}{llllll}
\hline Variable Items & Factors & Estimate & S.E. & Z-Value. \\
\hline Resident Family relations & $<---$ & Family Structure & 1.000 & & \\
New family members & $<--$ & Family Structure & 1.370 & .218 & 6.298 \\
Physical \& visual privacy & $<---$ & Family Structure & .701 & .130 & 5.381 \\
Children growth to adolescent & $<---$ & Family Structure & .800 & .133 & 6.023 \\
Length of Family Residency & $<---$ & Family Structure & .803 & .140 & 5.713 \\
House help accommodation & $<---$ & Family Values & 1.000 & & \\
Interaction with neighbours & $<---$ & Family Values & 1.066 & .201 & 5.312 \\
Domestic activity spaces & $<---$ & Family Values & .802 & .172 & 4.648 \\
Neighbourhood social blend & $<---$ & Family Lifestyle & 1.000 & & \\
Status elevation & $<---$ & Family Lifestyle & .879 & .150 & 5.880 \\
Outdoor relaxation areas & $<---$ & Family Lifestyle & 1.031 & .150 & 6.882 \\
Domestic animals rearing & $<---$ & Family Lifestyle & 1.109 & .172 & 6.466 \\
Ethnic reflection & $<---$ & Social Identity & 1.000 & & \\
Hosting tribesmen guest & $<---$ & Social Identity & .926 & .092 & 10.033 \\
Family status reflection & $<---$ & Social Identity & .570 & .087 & 6.532 \\
Ethnic identity & $<---$ & Social Identity & .927 & .095 & 9.779 \\
Public housing prior experience & $<---$ & Social Identity & .514 & .083 & 6.213 \\
Male out door relaxation & $<---$ & Social Activities & .933 & .138 & 6.781 \\
\hline
\end{tabular}

Notes. $\mathrm{p}<0.01$, significant, except for New family members where $\mathrm{p}=0.078$ not significant

\section{Appendix B}

Questionnaire: Socio-Cultural factors of Public housing transformation towards user satisfaction

\section{Socio-demographic}

1. Place of origin 2. Occupation. 3. Employment status. 4. Age.

5. House tenure-ship Owner occupier (purchased) [ ] Tenant (rent) [ ] Inherited (family asset) [ ] others specify... 6. Indicate the no of years you have lived in the house. .7. Family size

8. Number of wives...........9. Number of children............. 10. Number of relatives living with you..............

11. How many elderly dependents are living with the family.

12. Which part of the country did you grow up and spent most of your life.

\section{Family Values}

1. You accommodate house helps in the compound for cooking \& general cleaning services.

2. Preparation of meals by traditional utensils required outdoor cooking spaces attach to kitchen.

3. Female members receive guests in private room other than the living room.

4. Interaction with neighbours guided adjustments to outdoor areas.

5. Internal privacy was a pre-determinant to the spatial changes made in the house.

6. Toilet facilities were separated between children \& adults in the house.

7. The need for family domestic chores \& services' spaces led to the provision of outdoor spaces.

\section{Family lifestyle}

8. Accommodating pets/domestic animals in the house influenced changes made.

9. Modifications were made in defining an outdoor relaxation space.

10. Future plan for a polygamous family influenced changes made to the house.

11. Elevation in status and occupation had effect on changes made to the house.

12. Adjustments were made to fit socially with the pattern of housing in the neighbourhood.

\section{Social activities}

13. Absence of children play area outside the compound influenced outdoor changes. 
14. Accommodating overnight relation led to providing additional spaces.

15. Courtyard was introduced for social gatherings and events.

16. Occasional outdoor cooking necessitated redefining cooking space around the courtyard.

17. Summer season influenced provision of outdoor functional spaces.

18. Existing toilet, kitchen and laundry facilities became overstretched and needed additions.

19. Accommodating visitors and friends led to the provision of additional spaces.

20. Space requirement for family study area influenced changes made.

\section{Family Structure}

21. There was need for additional accommodation to suite changed household structure.

22. New spaces were created to accommodate family relations living with the nuclear family.

23. Gender physical \& visual privacy of family members motivated redistribution of spaces.

24. The family's polygamous structure led to providing accommodation for new members.

25. Children's growth into adolescents and the desire for separate rooms informed adjustments.

26. Length of residency influence the phases of changes embarked upon.

\section{Social Identity}

27. Adjustments were made to reflect my ethnic origin in the house.

28. Hosting ethnic events \& entertaining community tribesmen informed changes made.

29. House layout was improved in order to reflect the family's occupation and status.

30 . Some elements and spaces in the house were desired to portray your ethnic identity.

31. The changes effected are similar with what is obtainable in the neighbourhood.

32. Prior knowledge of background culture informed permanent modifications to the house.

\section{Copyrights}

Copyright for this article is retained by the author(s), with first publication rights granted to the journal.

This is an open-access article distributed under the terms and conditions of the Creative Commons Attribution license (http://creativecommons.org/licenses/by/3.0/). 